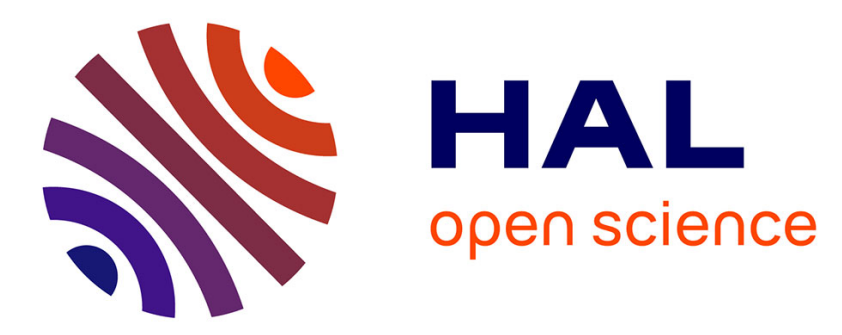

\title{
The cost of parasitism: High larval developmental mortality following attacks by a parasitoid fig wasp on a fig pollinating wasp
}

Xiao-Wei Zhang, Chun Chen, Rui-Wu Wang, Finn Kjellberg

\section{- To cite this version:}

Xiao-Wei Zhang, Chun Chen, Rui-Wu Wang, Finn Kjellberg. The cost of parasitism: High larval developmental mortality following attacks by a parasitoid fig wasp on a fig pollinating wasp. Acta Oecologica, 2020, 105, pp.103570. 10.1016/j.actao.2020.103570 . hal-02921735

\section{HAL Id: hal-02921735 \\ https://hal.science/hal-02921735}

Submitted on 25 Aug 2020

HAL is a multi-disciplinary open access archive for the deposit and dissemination of scientific research documents, whether they are published or not. The documents may come from teaching and research institutions in France or abroad, or from public or private research centers.
L'archive ouverte pluridisciplinaire HAL, est destinée au dépôt et à la diffusion de documents scientifiques de niveau recherche, publiés ou non, émanant des établissements d'enseignement et de recherche français ou étrangers, des laboratoires publics ou privés. 


\title{
The cost of parasitism: High larval developmental mortality following attacks by a parasitoid fig wasp on a fig pollinating wasp
}

Xiao-Wei Zhang ${ }^{\mathrm{a}}$, Chun Chen ${ }^{\mathrm{b}}$, Rui-Wu Wang ${ }^{\mathrm{a}}$, Finn Kjellberg ${ }^{\mathrm{c}}$

${ }^{a}$ Center for Ecological and Environmental Sciences, Northwestern Polytechnical University, Xi'an, Shaanxi, 710072, PR China ${ }^{\mathrm{b}}$ Statistics and Mathematics College, Yunnan University of Finance and Economics, Kunming, Yunnan, 650221, PR China ${ }^{\mathrm{c}}$ CEFE, CNRS, Univ Montpellier, Univ Paul Valéry Montpellier 3, EPHE, IRD, Montpellier, France

https://doi.org/10.1016/j.actao.2020.103570

\begin{abstract}
Parasitoids contribute to controlling phytophagous insect populations. Their action on a host is often measured by numbers of emerging adult parasitoids. However, parasitoid oviposition attempts may lead to host mortality and sometimes both host and parasitoid die during larval development. Therefore, establishing the effect of parasitoids on host populations requires estimating total effect of parasitoids.

The communities of wasps developing in figs (the closed inflorescences of Ficus) have become a model system to investigate micro-hymenopteran interaction networks. A galled ovule produces either a single galling wasp or a single parasitoid providing a simple way to measure costs. However, some galled flowers produce no wasps. We show that about one quarter of galled flowers fail to produce pollinator offspring in the absence of parasitoids. In the presence of parasitoids, the number of empty galls is increased. For each emerging parasitoid, 1.9 pollinator larvae were killed. Hence, host mortality induced by parasitoids is much larger than actual parasitoid production, a feature documented in some other host-parasitoid interactions and that may be pervasive in nature
\end{abstract}

Keywords: Ficus racemosa, parasitoid, demography

\section{Introduction}

Parasitoid hymenoptera represent the most diversified lineage of insects (Forbes et al., 2018). They can exert strong control of host populations (Godfray, 1994). As such, they provide natural ecological services (Losey and Vaughan, 2006) and they are largely used as biological control agents (Wang et al., 2019). The effect of parasitoids on a host may be measured as numbers of emerging parasitoids. However, actual parasitism levels may be much higher as joint mortality of host and parasitoid larva is increasingly documented, especially using nextgeneration sequencing (Sow et al., 2019). Other factors, such as parasitoid ovipositor probing, may also result in increased mortality (Abram et al., 2019). An extreme situation was observed for Itoplectis conquisitor (Say) ovipositing on Lymantria dispar, with 200 hosts killed by oviposition attempts for one successfully developed parasitoid offspring (Campbell, 1963). Such mortality has mainly been investigated for some invasive host species and for some parasitoids that are bred for biological control (Abram et al., 2016). It is difficult to obtain a global vision on the prevalence of host mortality that does not lead to parasitoid production in natural host-parasitoid communities as they are generally complex with a diversity of more or less specialized parasitoids feeding on a set of hosts (Stone et al., 2012).

Fig trees and their host-specific associated communities of fig wasps constitute a tractable model system to investigate the ecology and evolution of wasp communities (Cook and Rasplus, 2003). Because fig wasps are fig specialists, it is possible to collect the complete regional diversity of fig wasps by collecting wasps on the whole set of Ficus species. Levels of host specificity can be established (Farache et al., 2018). Unique 
insights may be obtained. For instance, observations throughout the range of a Ficus species has evidenced the presence of series of mutually exclusive parapatric sister species, demonstrating competition between species in a saturated community (Darwell and Cook, 2017).

Ficus are characterized by their enclosed urn-shaped inflorescence whose inside is lined by uniovulate pistillate flowers and some male flowers. Pollinating wasps enter figs and oviposit in the pistillate flowers. A pistillate flower will either give a seed or turn into a gall that will eventually produce one wasp. Usually, a Ficus species is pollinated locally by a single pollinating fig wasp species while it can host multiple nonpollinating fig wasps (Borges, 2015). Non-pollinating fig wasp (NPFW) communities include gallers, inquilines, kleptoparasites, parasitoids of the pollinators, parasitoids of other non-pollinating wasps, and hyperparasitoids and can be particularly diverse, with up to 30 or more species present on a single tree (Compton and Hawkins, 1992). As the pollinators, non-pollinating fig wasps oviposit into ovules and, whatever the species, a single non-pollinating wasp individual emerges from an ovule. Most non-pollinating wasp species have very long ovipositor that allow them to lay their eggs from outside the fig through the figwall. The timing of oviposition of the different species is scattered throughout the development of the fig (Wang and Qi, 2008).

Despite the interest for non-pollinating fig wasps biology, most studies are based on observations of timing of oviposition and correlations between the number of wasps of different species produced within a fig (Bronstein, 1991; Cardona et al., 2013; Kerdelhue and Rasplus, 1996; Krishnan and Borges, 2014; West et al., 1996). However, the results of correlation analysis can be very misleading as demonstrated by Raja et al. (2015): more productive figs produce more pollinators and more parasitoids resulting in a positive correlation between pollinator and parasitoid production (Raja et al., 2015). Lack of direct evidence for feeding regime may also obscure interpretations.

Ficus racemosa is one of the rare species for which the feeding regimes of the associated community of wasps is well described (Wang and Qi, 2008; Yadav and Borges, 2018). Using the pollinator of F. racemosa, Ceratosolen fusciceps and its single parasitoid, Sycophaga agraensis, we addressed the following questions: i) do we have evidence for larval mortality in Ceratosolen fusciceps in the absence of parasitism; ii) do we have evidence for reduced total wasp production in the presence of parasitoids iii) and is increased pollinator mortality affecting equally male and female pollinating wasps?

\section{Material and method}

The work was carried out in and around the Xishuangbanna Tropical Botanic Garden $\left(21^{\circ} 41^{\prime} \mathrm{N}, 101^{\circ} 25^{\prime}\right.$ E), Yunnan province, China. The altitude is approximately $600 \mathrm{~m}$ and the climate includes a wet and dry season. In Xishuangbanna, the wet season lasts from May to October.

A single crop on a single tree was used for the experimentation in order to reduce sources of variation. Indeed, our aim was to demonstrate the presence of an effect. We did not try to quantify the consequences of this effect on wasp population dynamics, as this will require much larger experimentation. The experiment consisted of two treatments. In one, we introduced 5 pollinating fig wasps per fig, and in the other treatment we introduced 5 pollinating wasps and then we exposed the fig to 10-20 parasitoid wasps.

We located trees that presented a crop of pre-receptive figs and enclosed randomly selected figs in nylon bags in order to prevent natural wasp colonization. The figs were monitored every three days. When the figs were close to the receptive stage (the stage at which pollinators are attracted and enter the figs), they were checked daily. When the figs were receptive, we deposited 5 pollinating wasps on each fig and let them enter. We used pollinating wasps that had emerged naturally from other trees. The figs were then enclosed individually in nylon bags to prevent further pollinator entries or uncontrolled parasitism by non-pollinating fig wasps. When the figs were ready for parasitoid oviposition (8-10 days after pollinator oviposition), we replaced the nylon bag enclosing the fig by a bag containing 10-20 parasitoid wasps and let the parasitoids 
oviposit. Several days later, when the parasitoid wasps had ceased oviposition, we replaced the bag with a new empty protective bag. After pollinating wasp introductions, we let the treated figs develop to maturity and collected the figs just after the wasps had emerged from the figs into the bag. Wasps and fig were then preserved in alcohol.

Each fig was longitudinally bisected twice along the ostiole-peduncle axis, so that the wasps still inside the fig cavity, the empty galls from which wasps had emerged, and galls containing dead wasps could be counted. We also counted the number of "bladders". These are empty, unperforated galls (bladders) similar in size and form to normal galls but lacking insects (Galil and Eisikowitch, 1971). They are generally interpreted as having been galled by ovipositing wasps but have become hollow due to early mortality of the wasp egg or embryo, (Galil and Eisikowitch, 1971; Jansen-González et al., 2012; Verkerke, 1989). Total gall numbers were calculated by summing numbers of exited galls, bladders, and those containing dead, nonemerged wasps.

\subsection{Data analysis}

We used the Shapiro-Wilk test to test the normality of the data of two treatments. The number of galls, wasps, and the sex ratio of pollinator offspring for the two treatments were normally distributed. Therefore, we used Student independent sample $t$-tests comparing gall numbers, pollinating wasp numbers and sex ratio of pollinating wasp between the two treatments. To analyze the relationship between the total number of wasps and the number of galls, two linear models in which the total number of wasps was set as explanatory variable and the gall number as the variable to be explained were used separately for the two treatments. Three other linear regression models were used to explore the quantitative effects of the presence of Sycophaga agraensis in this study. One linear model in which total gall number was set as explanatory variable and the number of Sycophaga agraensis as the variable to be explained was used to explore whether the number of offspring Sycophaga agraensis increases with gall number. To determine the effect of Sycophaga agraensis on the probability that a gall would give a wasp, we used a linear model in which the proportion of galls that produced a Sycophaga agraensis in each fig was set as explanatory variable and the proportion of the galls in which a wasp developed to become adult as the variable to be explained variable. To describe the relationship between offspring number of Sycophaga agraensis and pollinator, a linear model in which number of Sycophaga agraensis was set as independent variable and pollinator offspring number as dependent variable was used. The statistics were carried out with R 3.5.3.

\section{Results}

The number of galls did not differ between the two treatments (with and without parasitoid wasp) (893.82 \pm 45.97 versus $939.82 \pm 45.91$ (Mean $\pm \mathrm{SE}$ ), $\mathrm{t}=0.696$, $\mathrm{df}=37, \mathrm{P}=0.491$ ), while fewer wasps developed in parasitized figs than in figs into which only pollinators oviposited $(720.94 \pm 36.55$ versus $893.82 \pm 31.88$ (Mean $\pm \mathrm{SE}$ ), $\mathrm{t}=3.239$, $\mathrm{df}=37, \mathrm{P}<0.01$ ). The proportion of galls that produced a wasp was reduced in figs exposed to Sycophaga agraensis $(0.63 \pm 0.02$ versus $0.77 \pm 0.02$ versus (Mean $\pm \mathrm{SE}), \mathrm{t}=0.379$, $\mathrm{df}=37, \mathrm{P}<$ 0.001). The sex ratio (number of males divided by total number of pollinating wasps) of pollinating wasps did not differ between the two treatments $(0.291 \pm 0.012$ versus $0.286 \pm 0.008($ Mean $\pm \mathrm{SE}), \mathrm{t}=0.311$, $\mathrm{df}=$ $37, \mathrm{P}=0.758)$.

The number of pollinator offspring that developed in figs exposed to Sycophaga agraensis was reduced by one third $(472.18 \pm 29.99$ versus

$720.94 \pm 36.55$ versus(Mean \pm SE) $\mathrm{t}=5.309, \mathrm{df}=37$,

$\mathrm{P}<0.001$; Fig. 3). Both female pollinator offspring (338.73 \pm 22.84 versus $513.00 \pm 28.75$ versus (Mean \pm $\mathrm{SE}), \mathrm{t}=4.811$, df $=37, \mathrm{P}<0.001$; Fig. 3) and male pollinator offspring numbers declined in figs exposed to S. agraensis $(133.45 \pm 8.16$ versus $207.94 \pm 12.65$ (Mean $\pm \mathrm{SE}), \mathrm{t}=5.147$, df $=37, \mathrm{P}<0.001$; Fig. 3). The 
number of empty galls (bladders) was much higher in figs exposed to parasitoids (329.82 \pm 23.60 versus $218.88 \pm 19.18($ Mean $\pm \mathrm{SE}), \mathrm{t}=-3.495, \mathrm{df}=37, \mathrm{P}<0.01)$.

The total number of wasp offspring produced per fig correlated strongly with the total number of galls in both treatments, but the regressions were significantly different between the two treatments (Sycophaga agraensis absent: $\mathrm{y}=0.7297 \mathrm{x}+35, \mathrm{~N}=17, \mathrm{R}^{2}=0.84 \mathrm{p}<0.001 ;$ S. agraensis present: $\mathrm{y}=0.6087 \mathrm{x}+20, \mathrm{~N}=$ $22, \mathrm{R}^{2}=0.7703, \mathrm{p}<0.001$; test of difference between the two regressions, $\mathrm{F}_{2,35}=16.6, \mathrm{P}<10^{-4}$; Fig. 1). For the two correlations, the intercepts were not significantly different from zero.

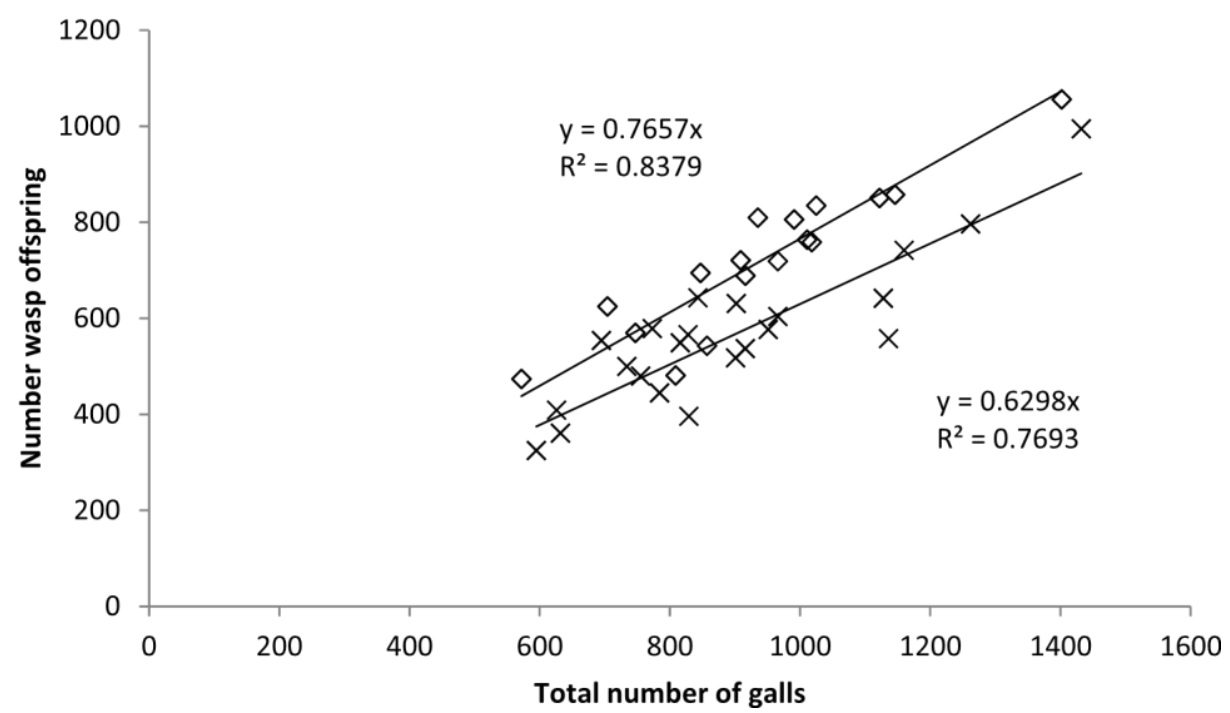

Fig. 1. Linear regression forcing the intercept to zero between the number of wasp offspring and the total number of galls when Sycophaga agraensis is absent or present. Open diamonds: S. agraensis absent; crosses: S. agraensis present

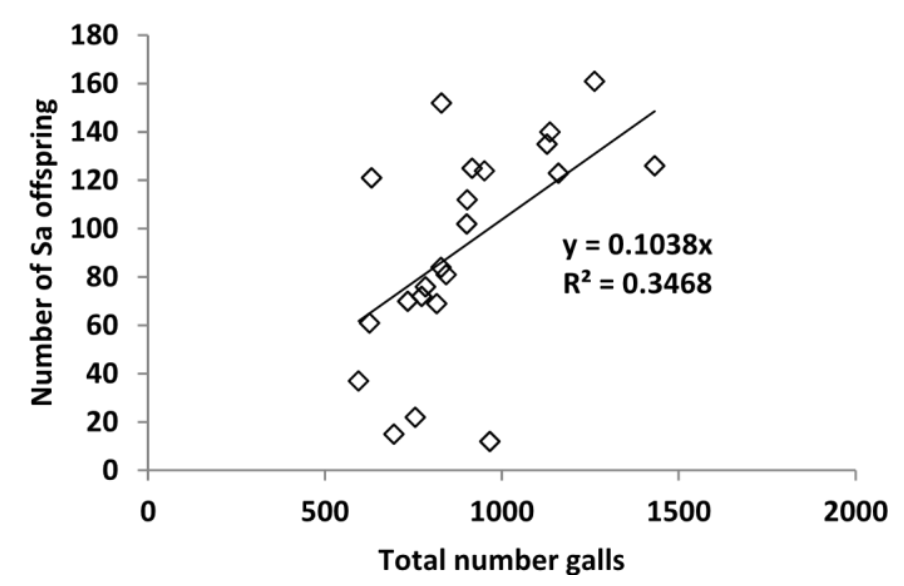

Fig. 2. Linear regression forcing the intercept to zero between the number of Sycophaga agraensis offspring and the total number of galls when $S$. agraensis is present. 


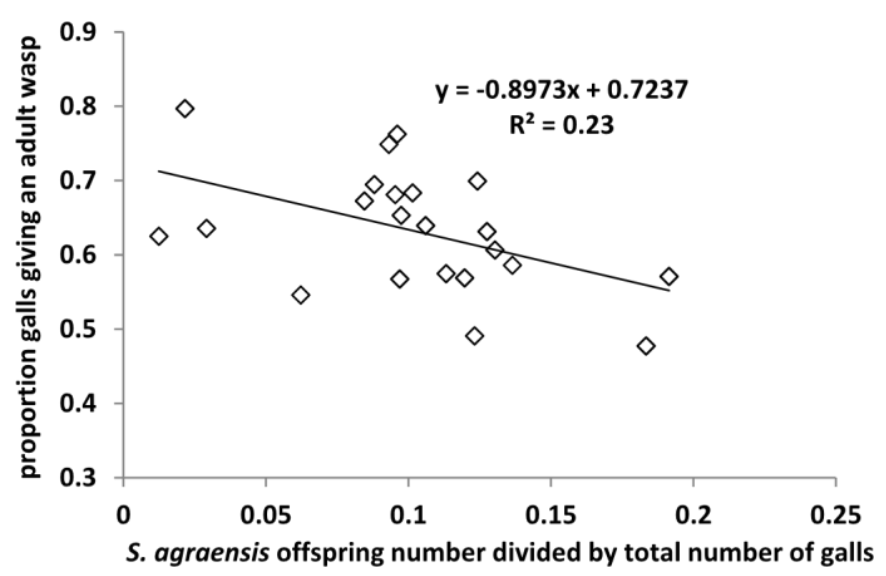

Fig. 3. Linear regression between overall development ratio and the relative number of Sycophaga agraensis offspring when it is present. The number of pollinator offspring produced was independent of the number of Sycophaga produced ( $\mathrm{y}=0.0156 \mathrm{x}+84.46, \mathrm{~N}=22, \mathrm{R}^{2}=0.0024, \mathrm{P}=0.83$; Fig. 4).

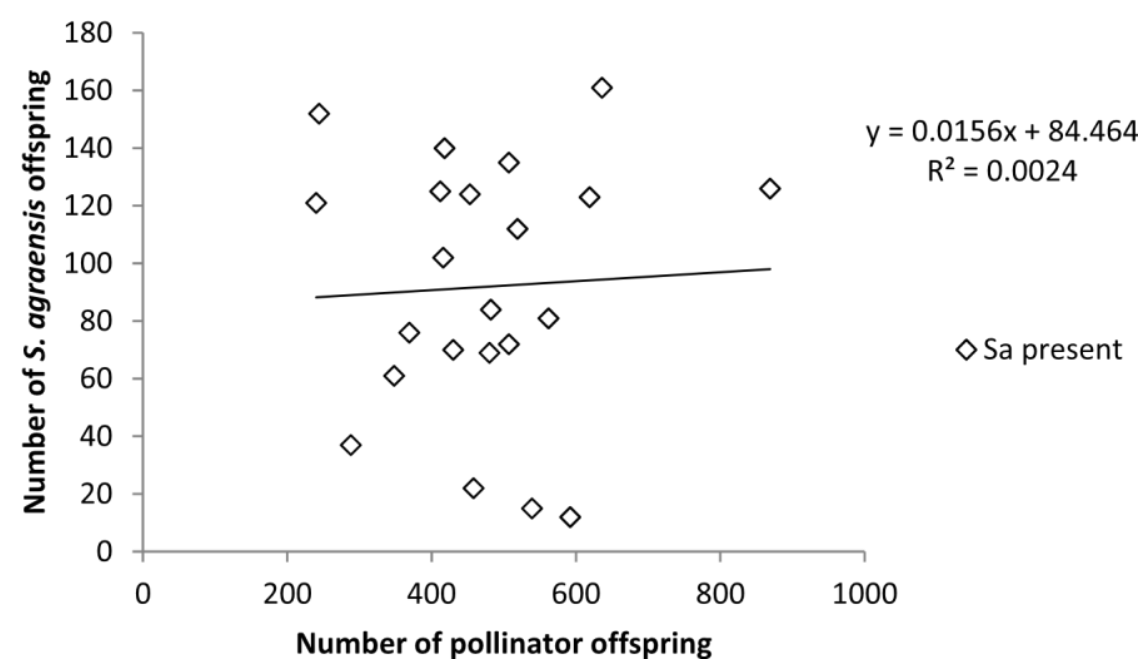

Fig. 4. Lack of correlation between number of pollinator offspring and number of Sycophaga agraensis offspring.

The number of Sycophaga agraensis produced correlates positively with the total number of galls: more productive figs produced more parasites $\left(\mathrm{y}=0.1224 \mathrm{x}-17.595, \mathrm{~N}=22, \mathrm{R}^{2}=0.3555, \mathrm{p}<0.01\right.$, intercept was not significantly different from zero, Fig. 2). The proportion of galls producing an insect correlated negatively with the ratio number of Sycophaga agraensis divided by total number of galls $(\mathrm{y}=-0.897 \mathrm{x}+0.725, \mathrm{~N}=22$, $\mathrm{R}^{2}=0.23 \mathrm{p}<0.05$; Fig. 3). The intercept (0.725) is the proportion of galls giving a wasp in the absence of parasitism. The slope gives the decrease in the proportion of galls giving a wasp as a function of the abundance of Sycophaga agraensis. For each additional Sycophaga, the total number of emerging wasps decreases by 0.897 , and hence the number of emerging pollinating wasps decreases by 1.897 .

In summary, figs without the parasitoid produced on average, 721 pollinators, 219 bladders, for a total of 940 galls while figs with parasitoids produced on average, 472 pollinators, 92 parasitoids, 330 bladders, for a total of 894 galls.

\section{Discussion}


In the absence of parasitoids, $27 \%$ of the galled flowers became bladders. These bladders could result from larval mortality or from gall initiation without oviposition. In Ficus montana, counts of the proportion of flowers into which pollinators had oviposited have shown i) that bladders corresponded to flowers into which a pollinator had oviposited and ii) that in the absence of parasitoids over 1/3 of the flowers that had received a pollinator egg turned into bladders (Ghana et al., 2012). We therefore accept as a provisional working hypothesis that there is a $27 \%$ larval mortality in Ceratosolen fusciceps. Similarly, in Ficus hirta figs into which one or two foundresses had been introduced, over $25 \%$ of the galled flowers were bladders, suggesting high larval mortality (Yu et al., 2018). Hence, despite 70 Ma coevolution between Ficus and their pollinating agaonid wasps (Cruaud et al., 2012), and despite aligned interests of plant and insect (Anstett et al., 1997), it appears that larval mortality remains remarkably high.

In the presence of parasitoids, the proportion of bladders (empty galls) was increased. This suggests either an increase in wasp developmental mortality or the initiation of new galls by the parasitoids. Initiation of new galls is unlikely because female flowers wilt rapidly after fig visitation by pollinators. Therefore, when Sycophaga agraensis oviposits into figs, 1-2 weeks after pollinator entry (Yadav and Borges, 2018), female flowers can probably no longer be galled. Further, the total number of galls did not increase in the presence of parasitoids confirming that no additional galls were initiated. The regressions show that for each additional Sycophaga produced, 0.9 additional bladder was present in the fig. Hence, the development of one parasitoid results in 1.9 fewer pollinator offspring. In the literature it is often implicitly assumed that the impact of pollinator-sized NPFWs is equal to the number of occupied ovaries, a galler larva occupying a single ovary and each parasitoid/kleptoparasite larva developing at the expense of one host wasp larva (Conchou et al., 2014). Indeed, the weight of a female individual of Sycophaga agraensis is identical to that of an individual Ceratosolen fusciceps, confirming that this parasitoid feeds on a single host (Ghara and Borges, 2010). Nevertheless, the data presented here suggests high larval mortality, even in pollinators, and one parasitoid replacing two pollinator larvae. Hence, there is no simple proxy to determine the cost to the mutualism of the different non pollinating fig wasps involved.

While we show that the reduction in total wasp production due to parasitism should not be neglected, our result do not provide an estimate of induced mortality values in natural populations and of the factors influencing this mortality. This will require investigating variation among crops within trees and among trees. Nevertheless, a similar result was obtained in Ficus sur: figs protected against parasitoid oviposition produced 1.5 time more wasps than those that were exposed to parasitoids (Compton and Robertson, 1988). Hence the phenomenon described here is probably general in fig wasps.

The results also show that we cannot estimate a cost of parasitism simply correlating host and parasite production. Indeed, in our data, despite each parasitoid costing two pollinators, the correlation between number of parasitoids produced and number of pollinators produced was not significant. This is because figs that initially contained more pollinator larvae were more parasitized.

The sex ratio strategies of pollinating fig wasps have been extensively studied (Herre, 1985; Raja et al., 2008). Sex ratio adjustment is achieved by females beginning by laying many males, and progressively reducing the proportion of males throughout oviposition (Raja et al., 2008). Females are selected to lay a higher proportion of males at the beginning of an oviposition sequence if the pollinating wasps have incomplete control over the number of male and female offspring (Kjellberg et al., 2005). The large pollinator larval mortality documented here could be an important factor limiting this control. Asymmetric effect of parasitoids on male and female pollinator offspring mortality could also affect sex ratio. In Ficus hirta, male pollinator offspring have been shown to be less exposed to parasitoids than female offspring, probably because their galls are located further from the fig wall, a factor that may limit the risk of a fig containing insufficient numbers of males to ensure female fertilization (Yu and Compton, 2012). This was not the case 
in our study and may relate to figs of Ficus racemosa generally containing many more wasp offspring than F. hirta figs. Larger broods automatically result in reduced sex ratio variance (Kjellberg et al., 2005), and hence reduced necessity to protect male offspring.

\section{Conclusion}

The study presented here confirms the necessity to take into account parasitoid effects on host mortality that do not simply result from the development of a parasitoid up to adult stage as suggested by (Abram et al., 2019). Neglecting these effects provides for a highly skewed vision of the effect of parasitoids on host populations.

\section{Funding}

This work was supported by the NSFC-Yunnan United fund [grant number U1302267]; the National Science Fund for Distinguished Young Scholars [grant number 31325005]; and the National Natural Science Foundation of China grants [grant number 31270433 to R.W. Wang, grant number 31760105 to C Chen].

\section{Role of authors}

XWZ devised the experiments, did the experiments, analysed the data and co-wrote the paper. CC participated in the experiments. RWW devised the experiments, analysed the data and co-wrote the paper. FK contributed to data analysis and co-wrote the paper.

\section{Declaration of competing interest}

The authors declare that they have no competing interests.

\section{Acknowledgments}

We thank Adrien Taudières for advices for the statistics. We thank XTGB for permission to work in the gardens and for access to the laboratory facilities of the research centre. We also thank Professor Yanqiong Peng for her hosting XWZ during the experiment at XTBG.

\section{References}

Abram, P.K., Brodeur, J., Burte, V., Boivin, G., 2016. Parasitoid-induced host egg abortion: an underappreciated component of biological control services provided by egg parasitoids. Biol. Contr. 98, $52-60$.

Abram, P.K., Brodeur, J., Urbaneja, A., Tena, A., 2019. Nonreproductive effects of insect parasitoids on their hosts. Annu. Rev. Entomol. 64, 259-276.

Anstett, M.C., HossaertMcKey, M., Kjellberg, F., 1997. Figs and fig pollinators: evolutionary conflicts in a coevolved mutualism. Trends Ecol. Evol. 12, 94-99.

Borges, R.M., 2015. How to be a fig wasp parasite on the fig-fig wasp mutualism. Curr. Opin. Insect Sci. 8, 34-40.

Bronstein, J.L., 1991. The nonpollinating wasp fauna of Ficus pertusa: exploitation of a mutualism? Oikos 61, 175-186.

Campbell, R.W., 1963. Some ichneumonid-sarcophagid interactions in the gypsy moth Porthetria dispar (L.)(Lepidoptera: lymantriidae). Can. Entomol. 95, 337-345.

Cardona, W., Kattan, G., Chacon de Ulloa, P., 2013. Non-pollinating fig wasps decrease pollinator and seed production in Ficus andicola (moraceae). Biotropica 45, 203-208.

Compton, S.G., Hawkins, B.A., 1992. Determinants of species richness in southern African fig wasp assemblages. Oecologia 91, 68-74. 
Compton, S.G., Robertson, H.G., 1988. Complex interactions between mutalisms: ants tending homopterans protect fig seeds and pollinators. Ecology 69, 1302-1305.

Conchou, L., Ciminera, M., Hossaert-McKey, M., Kjellberg, F., 2014. The non-pollinating fig wasps associated with Ficus guianensis: community structure and impact of the large species on the fig/pollinator mutualism. Acta Oecol. Int. J. Ecol. 57, 28-37.

Cook, J.M., Rasplus, J.Y., 2003. Mutualists with attitude: coevolving fig wasps and figs. Trends Ecol. Evol. 18, 241-248.

Cruaud, A., Rønsted, N., Chantarasuwan, B., Chou, L.S., Clement, W.L., Couloux, A., Cousins, B., Genson, G., Harrison, R.D., Hanson, P.E., 2012. An extreme case of plantinsect codiversification: figs and figpollinating wasps. Syst. Biol. 61, 1029-1047.

Darwell, C.T., Cook, J.M., 2017. Cryptic diversity in a fig wasp community-morphologically differentiated species are sympatric but cryptic species are parapatric. Mol. Ecol. 26, 937-950.

Farache, F., Cruaud, A., Rasplus, J.-Y., Cerezini, M., Rattis, L., Kjellberg, F., Pereira, R., 2018. Insights into the structure of plant-insect communities: specialism and generalism in a regional set of nonpollinating fig wasp communities. Acta Oecol. 90, 49-59.

Forbes, A.A., Bagley, R.K., Beer, M.A., Hippee, A.C., Widmayer, H.A., 2018. Quantifying the unquantifiable: why Hymenoptera, not Coleoptera, is the most speciose animal order. BMC Ecol. 18, 21.

Galil, J., Eisikowitch, D., 1971. Studies on mutualistic symbiosis between syconia and sycophilous wasps in monoecious figs. New Phytol. 70, 773-787.

Ghana, S., Suleman, N., Compton, S.G., 2012. Factors influencing realized sex ratios in fig wasps: double oviposition and larval mortalities. J. Insect Behav. 25, 254-263.

Ghara, M., Borges, R.M., 2010. Comparative life-history traits in a fig wasp community: implications for community structure. Ecol. Entomol. 35, 139-148.

Godfray, H.C.J., 1994. Parasitoids: Behavioral and Evolutionary Ecology. Princeton University Press. Herre, E.A., 1985. Sex-ratio adjustment in fig wasps. Science 228, 896-898.

Jansen-González, S., Teixeira, S.D.P., Pereira, R.A.S., 2012. Mutualism from the inside: coordinated development of plant and insect in an active pollinating fig wasp.

Arthropod-Plant Interact. 6, 601-609.

Kerdelhue, C., Rasplus, J.Y., 1996. Non-pollinating Afrotropical fig wasps affect the figpollinator mutualism in Ficus within the subgenus Sycomorus. Oikos 75, 3-14.

Kjellberg, F., Bronstein, J.L., van Ginkel, G., Greeff, J.M., Moore, J.C., Bossu-Dupriez, N., Chevolot, M., Michaloud, G., 2005. Clutch size: a major sex ratio determinant in fig pollinating wasps? Cr Biol. 328, 471-476.

Krishnan, A., Borges, R.M., 2014. Parasites exert conflicting selection pressures to affect reproductive asynchrony of their host plant in an obligate pollination mutualism. J.

Ecol. 102, 1329-1340.

Losey, J.E., Vaughan, M., 2006. The economic value of ecological services provided by insects. Bioscience 56, 311-323.

Raja, S., Suleman, N., Compton, S.G., Moore, J.C., 2008. The mechanism of sex ratio adjustment in a pollinating fig wasp. Proc. R. Soc. B 275, 1603-1610.

Raja, S., Suleman, N., Quinnell, R.J., Compton, S.G., 2015. Interactions between pollinator and nonpollinator fig wasps: correlations between their numbers can be misleading. Entomol. Sci. 18, $230-236$.

Sow, A., Brévault, T., Benoit, L., Chapuis, M.-P., Galan, M., Coeur d'acier, A., Delvare, G., Sembène, M., Haran, J., 2019. Deciphering host-parasitoid interactions and parasitism rates of crop pests using DNA metabarcoding. Sci. Rep. 9, 3646.

Stone, G.N., Lohse, K., Nicholls, J.A., Fuentes-Utrilla, P., Sinclair, F., Schönrogge, K., Csóka, G., Melika, G., Nieves-Aldrey, J.-L., Pujade-Villar, J., 2012. Reconstructing community assembly in time and space reveals enemy escape in a Western Palearctic insect community. Curr. Biol. 22, 532-537. 
Verkerke, W., 1989. Structure and function of the fig. Experientia 45, 612-622.

Wang, R.W., Qi, Z., 2008. Structure of a fig wasp community: temporal segregation of oviposition and larval diets. Symbiosis 45, 113-116.

Wang, Z.-Z., Liu, Y.-q., Min, S., Huang, J.-h., Chen, X.-X., 2019. Parasitoid wasps as effective biological control agents. J. Integr. Agric. 18, 705-715.

West, S.A., Herre, E.A., Windsor, D.M., Green, P.R.S., 1996. The ecology and evolution of the New World non-pollinating fig wasp communities. J. Biogeogr. 23, 447-458.

Yadav, P., Borges, R.M., 2018. Host-parasitoid development and survival strategies in a non-pollinating fig wasp community. Acta Oecol. 90, 60-68.

Yu, H., Compton, S.G., 2012. Moving your sons to safety: galls containing male fig wasps expand into the centre of figs, away from enemies. PloS One 7.

Yu, H., Compton, S.G., Wu, L., 2018. Spatial variation in pollinator gall failure within figs of the gynodioecious Ficus hirta. Acta Oecol. 90, 75-80. 